\title{
THE PROBLEMS OF MODERN METHODOLOGY OF COGNIZING PRIVATE LAW PHENOMENA
}

\author{
Olga S. Tolstova \\ Volgograd State University, Volgograd, Russian Federation \\ Ekaterina S. Pasharina \\ Volgograd State Academy of Physical Culture, Volgograd, Russian Federation
}

\begin{abstract}
Introduction: the methodology of cognizing legal phenomena is a set of methods, techniques by which the process of acquiring new knowledge about the lawtakes place. This understanding comes from the definition of methodology relevant to any scientific knowledge. In modern society, science is part of the spiritual culture of mankind. In this regard, the issues related to the methodology of science have a long history. The authors of the paper set the goal to theoretically substantiate the problems of modern methodology of cognizing private law phenomena. Methods: the methodological framework for the study consists of the methods of historicism, consistency, comparative law. Results: the author's point of view justified in the work is based on the knowledge of legal science, philosophy, and sociology. The question of methodological pluralism in the system of cognizing private law phenomena is raised. Conclusions: the study revealed the feature of private law research, consisting in their interdisciplinary nature. The complexity of modern social processes leads to the fact that law in its cognitive process must be based on the methodological knowledge of the following sciences, such as philosophy, history, sociology and many others. Using the integrated interdisciplinary approach in the framework of the methodology of cognizing legal phenomena, it is possible to solve the tasks of modern society.
\end{abstract}

Key words: methodology, methodology of cognition, reflection, the cognizing of law, legal sphere of cognition.

Citation. Tolstova O.S., Pasharina E.S. The Problems of Modern Methodology of Cognizing Private Law Phenomena. Legal Concept, 2019, vol. 18, no. 1, pp. 118-122. (in Russian). DOI: https://doi.org/10.15688/ lc.jvolsu.2019.1.16

УДК 340.1

ББК 66.011 .1
Дата поступления статьи: 11.01.2019 Дата принятия статьи: 15.02.2019

\section{ПРОБЛЕМЫ СОВРЕМЕННОЙ МЕТОДОЛОГИИ ПОЗНАНИЯ ЧАСТНОПРАВОВЫХ ЯВЛЕНИЙ}

Ольга Сергеевна Толстова

Волгоградский государственный университет, г. Волгоград, Российская Федерация

\section{Екатерина Сергеевна Пашарина}

Волгоградская государственная академия физической культуры, г. Волгоград, Российская Федерация

Введение: методология познания правовых явлений представляет собой совокупность методов, приемов, с помощью которых происходит процесс приобретения новых знаний о праве. Данное понимание исходит из определения методологии, относящейся к любому научному знанию. В современном обществе наука является частью духовной культуры человечества. Вопросы, относящиеся к методологии науки, имеют давнюю историю. Авторами данной работы поставлена цель, состоящая в теоретическом обосновании проблем современной методологии познания частноправовых явлений. Методы: методологическую основу составляют методы историзма, системности, стравнительно-правовой. Результаты: авторская позиция, обоснованная в работе, опирается на знания правовой науки, философии, социологии. Поднимается вопрос о 
методологическом плюрализме в системе познания частноправовых явлений. Выводы: в результате исследования выявлена особенность частноправовых исследований, состоящая в их междисплинарном характере. Сложность современных социальных процессов приводит к тому, что праву в своем познавательном процессе необходимо опираться на методологическое знание таких наук, как философия, история, социология и многие другие. Используя комплексный междисциплинарный подход в рамках методологии познания правовых явлений, можно решить поставленные задачи современного общества.

Ключевые слова: методология, методология познания, рефлексия, правопознание, правовая сфера познания.

Цитирование. Толстова О. С., Пашарина Е. С. Проблемы современной методологии познания частноправовых явлений // Legal Concept = Правовая парадигма. - 2019. - Т. 18, № 1. - C. 118-122. - DOI: https:// doi.org/10.15688/lc.jvolsu.2019.1.16

\section{Введение}

Проблема методологии познания права связана с общей методологией познания. В истории философии рассмотрение методологических вопросов восходит к трудам следующих ученых: древнегреческого философа Аристотеля, философов эпохи Нового времени Ф. Бэкона, Р. Декарта, Дж. Локка, немецких классиков И. Канта, Гегеля. Современное философское знание толкует понятие методологии с нескольких позиций. Во-первых, как тип рефлексивного сознания, который направлен на изучение закономерностей познания действительности. Во-вторых, как способ образования нового знания. В-третьих, как форма организации мыслительного процесса в определенной научной сфере. Философия видит в основе методологии мировоззренческие, идеологические компоненты [2, с. 32]. Мы считаем, что методология права представляет собой разновидность научной методологии. При этом она обладает своей спецификой, выраженной в особенности объекта познания и его цели.

\section{Философские методы исследования в юриспруденции}

Методология с позиции философского знания представляет собой дискуссионный вопрос. С одной стороны, это тип рефлексирующего знания, который направлен на изучение познания действительности. С другой стороны, с помощью методологии происходит выявление нового знания, его целей, установок. Иными словами, методология является особой формой организации деятельности индивидов. На наш взгляд, главной чертой методологии познания правовых явлений можно считать его рефлек- сивность, которая выражена в направленности на раскрытие процесса правопознания.

Большую роль в юриспруденции играют философские методы познания, задающие стратегию познания, определяющие парадигму дальнейшего исследования. Благодаря философскому знанию, точнее его принципам историзма, системности, единства предмета и метода, выстраивается методология познания права [3, c. 95-96]. В контексте развития современной науки особую роль в познании права занимает принцип историзма, согласно которому действительность развивается и изменяется во времени. Согласно данному принципу право рассматривается в определенных конкретно-исторических условиях во взаимосвязи с социальной жизнью. На основе этого принципа возникают исторический и генетический методы. Благодаря историческому методу в правовой сфере познания выявляются общее и особенное в историческом развитии правовой системы и права в частности и их взаимосвязь с социальной жизнью общества. Генетический метод направлен на изучение происхождения и становления права как явления, развивающегося в условии усложнения общественных отношений.

\section{Методологические компоненты права в системном подходе}

Системный подход направлен на изучение права как системы, через которую раскрывается целостность объекта. С одной стороны, право - это сложная система, состоящая из множества элементов. С другой стороны, право является одним из элементов более крупной системы под названием общество.

Для науки первостепенными являются накопление знаний, доказательность их истинно- 
сти. Необходимым условием развития научного знания является совершенствование методов познания, в основе которых лежит переход от эмпирического к теоретическому знанию.

В современной литературе методология права рассматривается как системная совокупность исследования правовых явлений с точки зрения их возникновения, функционирования и развития [4, с. 144]. Иными словами, представляет собой научный метод, на основе которого разрабатывается методология социологии права и происходит поиск новых решений. В основе методологии познания лежит организация самого исследования: нахождение критериев познания, поиск доказательств истинности. В процессе поиска нового знания обнажаются методология познания и ее характеристики. Используя ее, исследователь выявляет проблему. Иными словами, для того чтобы познать право, на первый план должны выйти критерии истинности юридического знания. В таких условиях необходим поиск методологических компонентов, с помощью которых возможно расширить и совершенствовать знания о праве. Каждая отрасль права определена своим предметом и имеет свой инструментарий. Так, задача правоведов состоит в расширении горизонтов познания с помощью применения новых концепций права. Изучая аспекты деятельности, исследователь синтезирует все имеющееся знание относительно того или иного вопроса. Таким образом, необходимо выяснить, что представляет собой методология в целом.

\section{Объективистские и субъективистские установки права}

Методология представляет собой систему установок как неких катализаторов, направленных на постижение предмета познания. Можно выделить следующие ее разновидности: диалектическую, антропологическую, феноменологическую, формально-логическую, социологическую, культурологическую, историческую, системную и аксиологическую. При анализе объектов в современном праве правоведы исследуют, например, диалектическую методологию, формальнологическую, основывающуюся на законах логики и понятийном мышлении.
Применение тех или иных методов в познании подчинено определенным нормам. В основе каждой методологии находится логика познания, которая выражена в методологических установках. Ключевыми среди последних являются объективистские и субъективистские. Рассмотрим их подробнее. В основе объективистских установок лежит идея относительно того, что метод связан с предметом исследования [2, с. 32]. Вспомним утверждение Г. Гегеля о том, что метод представляет имманентную душу предмета. Согласно данному пониманию методология познания правовых явлений должна соответствовать логике развития предмета. Субъективистская установка учитывает в процессе методологии сам предмет исследования и творческую составляющую, исходящую от личности. Приверженцем данной позиции является немецкий философ XIX в. И. Кант, который утверждал, что человек может познать только то, что создано им лично.

В методологии познания правовых явлений мы наблюдаем совмещения представленных методологических установок. Это связано со спецификой феномена права, то есть оно создается индивидом, но в то же время существует независимо от его воли. В этом плане субъективная установка в ходе правового познания раскрывает процесс возникновения права, а объективная - его функционирования.

Выбор методологии зависит от цели исследователя. Например, ею является познание особенностей правового развития, следовательно необходимо опираться на методические разработки в рамках исторических наук. В таком случае исторический подход направлен на познание природы права, особенностей формирования и эволюции института права. Согласно данному подходу исследователь должен сопоставить объект познания в правовой сфере на отрезке истории. В методологии права особую популярность получил сравнительно-правовой подход, в основе которого лежит идея культурноценностной детерминированности права. В его рамках большую роль имеет задача исследования. Благодаря антропологическому подходу право исследуется как среда существования человека. Исходя из феноменологического подхода, право является специфическим состоянием сознания, направленным на переживание правового опыта в правовой реальности. 
Таким образом, наличие множества подходов к методологии познания правовых явлений говорит о многомерности природы права и о необходимости новых исследований, изучающих взаимодействия в правовой сфеpe $[1$, c. 70$]$. Методология представляет собой объединяющее понятие, включающее в себя мировоззрение исследователя, которое не может быть в застывшем состоянии. Оно способствует новому развитию познания.

В современном мире наука характеризуется как комплекс социокультурных, гуманистических оснований. В сфере права наблюдается необходимость использования социокультурного подхода, который тесно связан с аксиологическим. В основе социокультурного подхода лежат средства постижения феномена культуры общества. При использовании концепции диалога культур право трактуется с новой позиции, при которой актуализируется роль традиции и преемственности в праве. Стоит отметить, что наблюдается активность правовых наук в отношении применения инструментария гуманитарных наук. Институциональный подход применяют при исследовании правовых явлений. Согласно данному подходу меняется трактовка политического института. С одной стороны, он представляет собой стабильный комплекс формальных и неформальных принципов, которые направлены на регуляцию различных сфер деятельности, с другой - он является общностью индивидов, связанных между собой с помощью социальных норм. Согласно синергетическому подходу любая система имеет способность к самоорганизации, в основе которой лежит хаотическое движение, приводящее к порядку. Правоведы, опираясь на данный подход в рассмотрении правовых явлений, считают последние зависимыми от этого процесса, происходящего в современном социуме.

Соответственно, наличие множества методологических подходов к исследованию права говорит о методологическом плюрализме, с помощью которого возможно преодолеть одностороннее рассмотрение правовых явлений.

Специфическим методом для области права является метод конструкции. В его осонове находится модель урегулирования правом общественных отношений. Исследова- тель выделяет из социальной действительности то, что является значимым и создает идеальную модель правового явления.

Совокупность методов научного познания включает в себя теоретические установки, условия, критерии познания, поиск доказательств истинности теории. Исследование в правовой сфере направлено на раскрытие новых подходов, на объяснение различных явлений правовой действительности. Анализируя правовую область, исследователь должен исходить из совокупности взглядов на право, синтезируя, систематизируя выводы.

\section{Выводы}

Исходя из анализа современных подходов к правопониманию, можно выявить взаимосвязь между типом правопонимания и методологическим подходом. В правовой литературе представлены следующие типы правопонимания: нормативное понимание права, естественно-правовая концепция, социологическая трактовка теории права. В связи с этим интерес представляет концепция интегрального понимания Г. Бермана. В ней автором предложен методологический подход к анализу права, в основе которого лежит творческий процесс и философское воззрение. В его понимании право - это объект познания, который находится в процессе обмена познавательными ресурсами и правоведческими подходами.

Современное общество с его процессами интеграции и информационными возможностями обеспечивает человеку отсутствие привязки к определенному государству. Поэтому необходимо критическое осмысление традиционных представлений о праве в его связи с государством.

Особенность правовых исследований состоит в их междисплинарном характере. Сложность современных социальных процессов приводит к тому, что праву в своем познавательном процессе необходимо опираться на методологическое знание следующих наук, например, философии, истории, социологии и многих других. Используя комплексный междисциплинарный подход в рамках методологии познания правовых явлений, можно решить поставленные задачи современного общества, связанные с усложнением соци- 
альных связей, появлением новых социальных регуляторов в управлении обществом.

\section{СПИСОК ЛИТЕРАТОРЫ}

1. Голик, Ю. В. Метод уголовного права / Ю. В. Голик // Журнал российского права. 2000. - № 1. - С. 69-75.

2. Жеребцова, Е. Е. К вопросу о понятии и структуре методологии исследования института судебного конституционного контроля / Е. Е. Жеребцова // Право и государство: теория и практика. 2010. - № 4. - С. 29-33.

3. Керимов, Д. А. Методология права: предмет, функции, проблемы философии права / Д. А. Керимов. - 3-е изд., перераб. и доп. - М. : Соврем. гуманит. акад., 2003. -520 c.

4. Яскевич, Я. С. Методология и этика в современной науке: поиск открытой рациональности : учеб.-метод. пособие / Я. С. Яскевич. - Минск : Белорус. гос. экон. ун-т, 2007. - 186 с.

\section{REFERENCES}

1. Golik Yu.V. Metod ugolovnogo prava [Method of Criminal Law]. Zhurnal rossiyskogo prava, 2000, no. 1 , pp. 69-75.

2. Zherebtsova E.E. K voprosu o ponyatii i strukture metodologii issledovaniya instituta sudebnogo konstitutsionnogo kontrolya [On the Concept and Structure of the Research Methodology of the Judicial Constitutional Control Institute]. Pravo i gosudarstvo: teoriya i praktika, 2010, no. 4, pp. 29-33.

3. Kerimov D.A. Metodologiya prava: predmet, funktsii, problemy filosofii prava [Methodology of Law: Subject, Functions, Problems of Philosophy of Law]. Moscow, Sovremennaya gumanitarnaya akademiya, 2003. 520 p.

4. Yaskevich Ya.S. Metodologiya i etika v sovremennoy nauke: poisk otkrytoy ratsionalnosti [Methodology and Ethics of Modern Science: the Search for Open Rationality]. Minsk, Belorusskiy gosudarstvennyy ekonomicheskiy universitet, 2007. 186 p.

\section{Information about the Authors}

Olga S. Tolstova, Senior Lecturer, Department of Civil and International Private Law, Volgograd State University, Prosp. Universitetsky, 100, 400062 Volgograd, Russian Federation, kosivcovaos@mail.ru, https://orcid.org/0000-0002-2984-4990

Ekaterina S. Pasharina, Candidate of Sciences (Philosophy), Associate Professor, Department of Social and Humanitarian Disciplines and Foreign Languages, Volgograd State Academy of Physical Culture, Prosp. Lenina, 78, 400005 Volgograd, Russian Federation, pasharina83@icloud.com, https:// orcid.org/0000-0002-3147-444X

\section{Информация об авторах}

Ольга Сергеевна Толстова, старший преподаватель кафедры гражданского и международного частного права, Волгоградский государственный университет, просп. Университетский, 100, 400062 г. Волгоград, Российская Федерация, kosivcovaos@mail.ru, https://orcid.org/0000-0002$2984-4990$

Екатерина Сергеевна Пашарина, кандидат философских наук, доцент кафедры социально-гуманитарных дисциплин и иностранных языков, Волгоградская государственная академия физической культуры, просп. им. В.И. Ленина, 78, 400005 г. Волгоград, Российская Федерация, pasharina83@icloud.com, https://orcid.org/0000-0002-3147-444X 